\section{Endoscopic snare polypectomy of a pedunculated adenocarcinoma of the duodenal bulb arising from a hyperplastic polyp}

Primary non-ampullary adenocarcinoma of the duodenum is a rare occurrence, arising mainly from adenomatous polyps [1]. We report the first case of a pedunculated adenocarcinoma of the duodenal bulb, arising from a hyperplastic polyp, treated with endoscopic snare polypectomy.

A 76-year-old man underwent esophagogastroduodenoscopy (OGD) for asymptomatic iron-deficiency anemia. A 2-cm pedunculated polyp in the duodenal bulb ( $\bullet$ Fig. 1) and a small antral polyp were noted. Snare polypectomy of the pedunculated polyp was performed. Histopathology revealed a polyp sharing microscopic similarities to hyperplastic gastric polyps with hyperplastic irregular crypts, basal cystic change, and a focally retained villiform surface. Reactive eosinophilic syncytial cells with large vesicular nuclei were present along with foci of severe dysplasia and possible early invasion $(\bullet$ Fig. 2 and $\bullet$ Fig.3). Antral biopsies revealed Helicobacter pylori gastritis and a hyperplastic polyp with low grade dysplasia. A colonoscopy, staging computed tomography (CT) scan, and small-bowel barium studies were normal.

Following treatment of the patient with triple therapy and proton pump inhibitors, a repeat OGD at 3 months confirmed $H$. pylori eradication but showed high grade dysplasia of the stomach body. Subsequent OGDs at 6 months and 1 year showed downstaging to low grade dysplasia and intestinal metaplasia respectively. The patient is due for a repeat OGD in 1 year.

Incidental non-ampullary duodenal polyps are frequently encountered at endoscopy, and are mostly of an adeno- matous nature, especially if $\geq 10 \mathrm{~mm}$ in size [2]. While adenomas are premalignant for duodenal adenocarcinoma [1], hyperplastic polyps in the stomach and colon have also rarely been shown to possess malignant potential [3]. Progression of duodenal hyperplastic polyps though remains uncertain [4]. This case is the first to report malignant transformation from a hyperplastic polyp occurring in the duodenum, emphasizing the importance of complete excision of such polyps. Endoscopic snare polypectomy is safe when polyps are pedunculated [5], as in our case.

Endoscopy_UCTN_Code_CCL_1AB_2AZ_3AB

\section{Competing interests: None}

\section{J. Gerada ${ }^{1}$, D. Babic ${ }^{2}$, J. Degaetano², J. Pocock ${ }^{1}$}

${ }^{1}$ Division of Gastroenterology, Mater Dei Hospital, Msida, Malta

${ }^{2}$ Department of Histopathology, Mater Dei Hospital, Msida, Malta
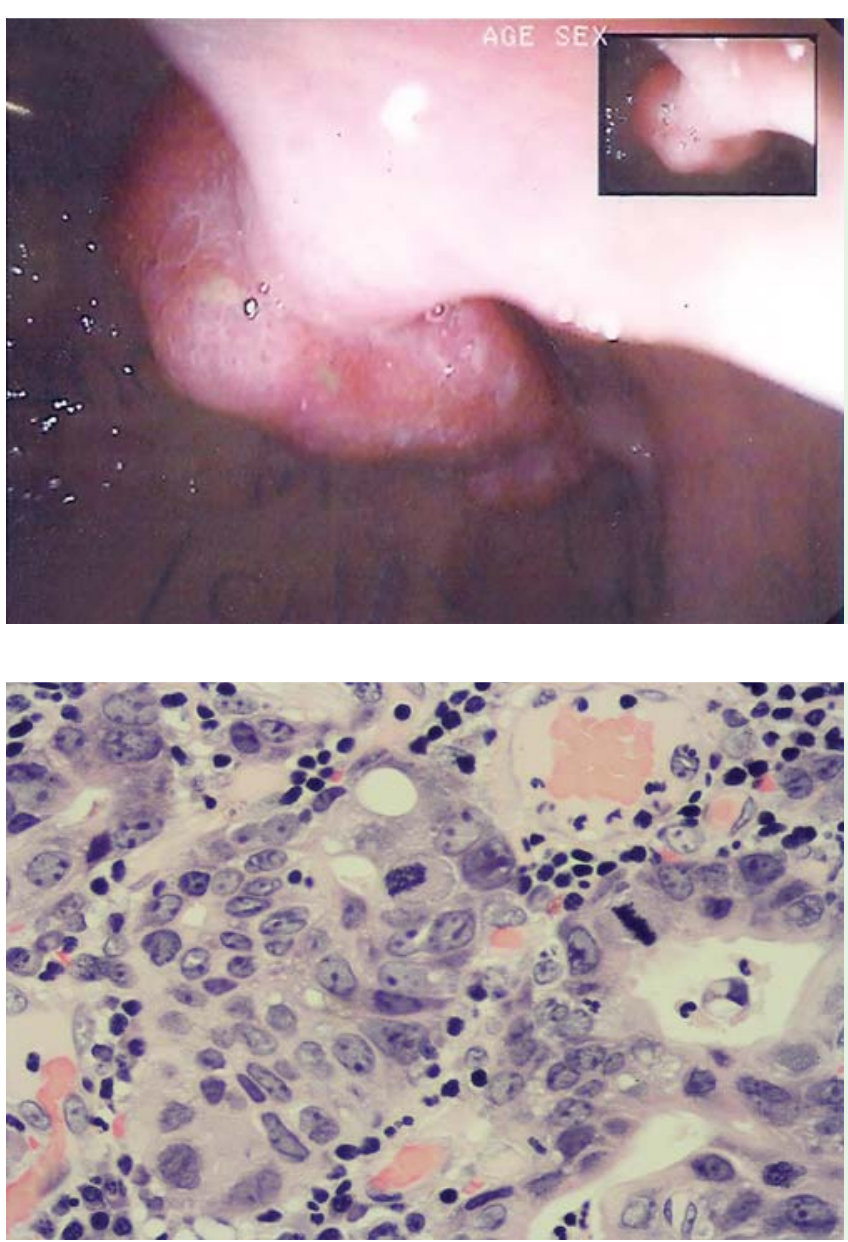

Fig. 1 Pedunculated polyp in the duodenal bulb before endoscopic snare polypectomy.

Fig. 3 Scattered abnormal mitoses (hematoxylin and eosin, $\times 650$ ).

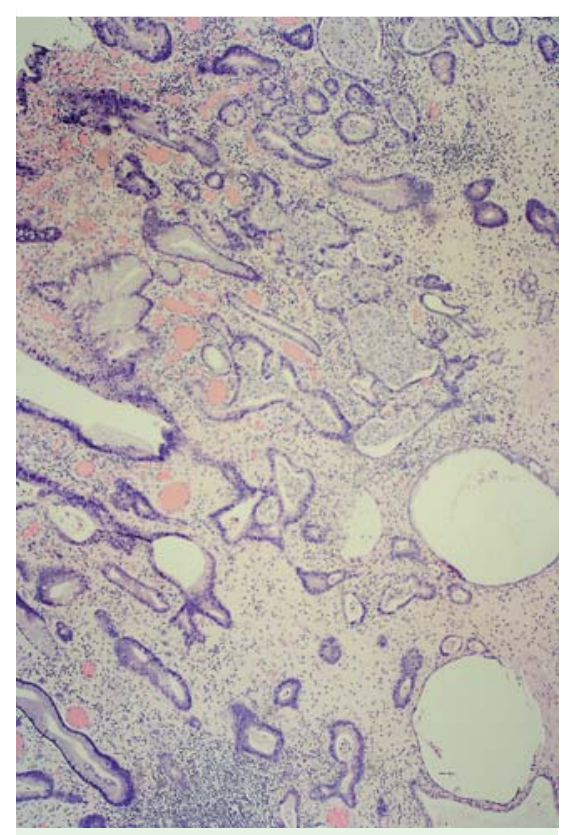

Fig. 2 Basal cystic change in crypts, and crypt epithelial atypia (hematoxylin and eosin, $\times 50$ ). 


\section{References}

1 Culver EL, McIntyre AS. Sporadic duodenal polyps: classification, investigation, and management. Endoscopy 2011; 43: $144-$ 155

2 Abbass R, Rigaux J, Al-Kawas F. Nonampullary duodenal polyps: characteristics and endoscopic management. Gastrointes Endosc 2010; 71: 754-759

3 Okano A, Takakuwa H, Matsubayashi Y. Gastric intramucosal carcinoma in a small hyperplastic foveolar polyp. Endoscopy 2004; 36: 1134
4 Rosty C, Buchanan D, Walters $R$ et al. Hyperplastic polyp of the duodenum: a report of 9 cases with immunohistochemical and molecular findings. Hum Pathol 2011; 42: 1953 1959

5 Kawaratani H, Tsujimoto T, Nishimura $N$ et al. A case of lobulated and pedunculated duodenal hyperplastic polyp treated with snare polypectomy. Case Rep Gastroenterol 2011; 5: $404-410$

\section{Bibliography}

Dol http://dx.doi.org/ 10.1055/s-0032-1309395

Endoscopy 2012; 44: E244-E245

(c) Georg Thieme Verlag KG

Stuttgart · New York

ISSN 0013-726X

\section{Corresponding author}

J. Gerada, MD

Mater Dei Hospital

Msida

Malta

Fax: +356-25457582

jurgen.gerada@gmail.com 